\title{
Molecular cloning and preliminary function study of iron responsive element binding protein 1 gene from cypermethrin-resistant Culex pipiens pallens
}

Wenbin Tan ${ }^{*}$, Xiao Wang ${ }^{1}$, Peng Cheng ${ }^{2}$, Lijuan Liu², Haifang Wang ${ }^{2}$, Maoqing Gong ${ }^{2}$, Xin Quan Honggang Gao ${ }^{1}$ and Changliang $\mathrm{Zhu}^{3}$

\begin{abstract}
Background: Insecticide resistance jeopardizes the control of mosquito populations and mosquito-borne disease control, which creates a major public health concern. Two-dimensional electrophoresis identified one protein segment with high sequence homology to part of Aedes aegypti iron-responsive element binding protein (IRE-BP).

Method: RT-PCR and RACE (rapid amplification of CDNA end) were used to clone a CDNA encoding full length IREBP 1. Real-time quantitative RT-PCR was used to evaluate the transcriptional level changes in the Cr-IRE strain Aedes aegypti compared to the susceptible strain of $C x$. pipiens pallens. The expression profile of the gene was established in the mosquito life cycle. Methyl tritiated thymidine $\left({ }^{3} \mathrm{H}-\mathrm{TdR}\right)$ was used to observe the cypermethrin resistance changes in C6/36 cells containing the stably transfected IRE-BP 1 gene of CX. pipiens pallens.

Results: The complete sequence of iron responsive element binding protein 1 (IRE-BP 1) has been cloned from the cypermethrin-resistant strain of Culex pipiens pallens (Cr-IRE strain). Quantitative RT-PCR analysis indicated that the IRE-BP 1 transcription level was 6.7 times higher in the Cr-IRE strain than in the susceptible strain of 4th instar larvae. The IRE-BP 1 expression was also found to be consistently higher throughout the life cycle of the Cr-IRE strain. A protein of predicted size 109.4 kDa has been detected by Western blotting in IRE-BP 1-transfected mosquito C6/36 cells. These IRE-BP 1-transfected cells also showed enhanced cypermethrin resistance compared to null-transfected or plasmid vector-transfected cells as determined by ${ }^{3} \mathrm{H}-\mathrm{TdR}$ incorporation.
\end{abstract}

Conclusion: IRE-BP 1 is expressed at higher levels in the Cr-IRE strain, and may confer some insecticide resistance in CX. pipiens pallens.

\section{Background}

Mosquitos are one of the medically important insects closely related to the life of human beings. The harm caused by mosquitoes to human beings is not only because of the harassment and blood feeding habits, but also in the transmission of various diseases, such as malaria [1], filariasis [2], yellow fever [3], dengue [4], and Japanese encephalitis [5]. It requires enormous efforts to overcome these diseases, which include

\footnotetext{
* Correspondence: 1392144@163.com

'Department of Pathogenic Biology, Jining Medical University, Jining,

Shandong Province, 272067, PR China

Full list of author information is available at the end of the article
}

environmental management, the use of insecticides and repellents, vaccine research and biological mosquito control [6-8]. Insecticides play a central role in controlling mosquitoes, but today, more and more serious insecticide resistance has appeared in mosquitoes, and against every chemical class of insecticides, such as Organochlorine, carbamate, organophosphate, pyrethroid and insect growth regulators [9-11]. Insecticide resistance jeopardizes the control of mosquito populations and mosquito-borne disease control, which creates a major public health concern [12-14].

Pyrethroids [15] are a group of chemicals that interact with insect ion channels causing a disruption to 
transmembrane potentials, therefore interfere with the normal functions of the insect nerve system. As a member of pyrethroids, cypermethrin [16] is commonly used for the treatment of bed nets and as a residual spray to help control mosquito population and disease transmission, such as malaria. Unfortunately the wide spread use and incorrect application of cypermethrin and other synthetic pyrethroids has accelerated the emergence of resistance in both targeted Anopheles species and offtarget species such as $C x$. pipiens pallens [17]. The elucidation of the resistance mechanism becomes important to guide the use of cypermethrin and the development of its substitutes.

To study the mechanism of cypermethrin resistance, a resistant strain of $C x$. pipiens pallens, Cr-IRE, has been previously established in the laboratory of Shandong Institute of Parasitic Diseases by selecting stadium larvae with increasing concentrations of cypermethrin over 39 generations, and the cypermethrin-resistant level is 160.43 times higher than that of the sensitive strain [18]. Two-dimensional electrophoresis was used to screen differences in protein expression (Data not shown). One of the identified protein segments has high sequence homology to part of Aedes aegypti ironresponsive element binding protein (IRE-BP). Iron is necessary for a number of essential cell functions but, as excessive amounts can be toxic, iron metabolism is carefully controlled at both cellular and systemic levels. One of the iron homeostasis regulatory proteins is IRE-BP. IRE-BP is a cytosolic protein that binds a highly conserved sequence in the untranslated regions of mRNAs involved in iron metabolism including ferritin, IRE-BP 1 receptor, and erythroid 5-aminolevulinate acid synthase [19]. IRE-BPs has remained highly conserved during evolution. Iron-responsive elements (IREs) are regulatory RNA elements, which serve as specific binding sites for the IRE-binding protein (IRE-BP). Interaction between IREs and IRE-BP induces repression of ferritin mRNA translation and IRE-BP 1 receptor mRNA stabilization [20]. But the correlation between the function of IRE-BP 1 and insecticide resistance has not been reported to date.

In the present study, we utilized RT-PCR and RACE (rapid amplification of cDNA end) to clone a cDNA encoding full length IRE-BP 1 . The nucleotide sequence of the clone was subsequently determined. Real-time quantitative RT-PCR indicated that this gene is transcribed to a greater extent in the Cr-IRE strain than in the susceptible strain of $C x$. pipiens pallens. We also established the expression profile of the gene in the mosquito life cycle. Increased cypermethrin resistance in C6/36 cells containing the stably transfected IRE-BP 1 gene provided further support for a role of IRE-BP 1 in cypermethrin resistance in $C x$. pipiens pallens.

\section{Materials and methods \\ Mosquitoes}

Cr-IRE strain and the susceptible strain of Cx. pipiens pallens mosquitoes used in this study were reared at $28^{\circ}$ $\mathrm{C}$ with $70-80 \%$ humidity and a constant light:dark cycle (14:10). The mosquitoes were fed with mouse blood. The Cr-IRE colony has been selected from a susceptible strain [18], and the resistance has been maintained by treatment with cypermethrin at $\mathrm{LC}_{50}$ of each generation. The $\mathrm{LC}_{50}$ of Cr-IRE strain is $3.322 \mathrm{mg} / \mathrm{L}, 81$-fold greater than that in the susceptible strain $(0.041 \mathrm{mg} / \mathrm{L})$.

\section{RNA extraction, 5'RACE PCR and RT-PCR}

Total RNA was extracted from approximately $20 \mathrm{mg}$ of 1st, 2nd, 3rd and 4th instar larvae and female adult $C x$. pipiens pallens mosquitoes, using Trizol reagent (Gibco BRL, Grand Island, NY, USA) according to the manufacturer's protocol. The amplification of the 5' end of IRE-BP 1: forward primer: nested universal primer mix (UPM) was provided by the kit: (Primer 1, Table 1), reverse primer: designed based on the sequence reported by Saitoh, Y., [21] (GenBank Accession No. D16150.1): (Primer 2, Table 1). The amplification of the 3' end of IRE-BP 1: forward primer: designed based on the sequence reported by Saitoh, Y. [21] (GenBank Accession No. D16150.1): (Primer 3, Table 1), reverse primer: use the UPM primer proved by the 3'-RACE Kit: (Primer 4, Table 1). The cDNA fragments were successfully amplified and separated by electrophoresis on a $1 \%$ agarose gel. The cDNA fragment of interest was purified using a quick gel extraction kit (Qiagen, Hilden, Germany), and ligated into a pGEMT-easy vector (Tianwei,

Table 1 Primers used in the experiments

\begin{tabular}{|c|c|}
\hline Primer & Sequence \\
\hline 1 & 5'-AAGCAGTGGTATCAACGCAGAG-3' \\
\hline 2 & 5'-GAGCCTGGTGGAATAATCCTCAT-3' \\
\hline 3 & $5^{\prime}$-cactgacgtggaactcacttac $T-3^{\prime}$ \\
\hline 4 & 5'-CTAATACGACTCACTATAGGGC-3? \\
\hline 5 & $5^{\prime}$-atggctggtcctaacccctttca-3' \\
\hline 6 & 5'- TTAGGCAATCATCTTCCTGATCAT-3' \\
\hline 7 & 5'-GTGGCGAAGAGATGGATG-3' \\
\hline 8 & 5'-ACGAACAATAACCTGGAACT' \\
\hline 9 & 5'-AGCGTGAACTGACGGCTCTTG-3' \\
\hline 10 & 5'-ACTCGTCGTACTCCTGCTTGG-3' \\
\hline 11 & 5'-TACGGTGGTGCGGCTTAT-3' \\
\hline 12 & 5'-CAGGGTGAAATCTGATGGTT-3' \\
\hline 13 & $5^{\prime}$-atggctggtcctaacccctttca-3' \\
\hline 14 & 5'-GGCAATCATCTTCCTGATCATGT-3' \\
\hline 15 & $5^{\prime}-$ atggctggtcctaacccctttca-3' \\
\hline 16 & 5'-GTTAGGGATAGGCT TACCTTCG-3' \\
\hline 17 & 5'-CACCAGGGTGTGATGGTCGG-3' \\
\hline 18 & 5'-CCACCGATCCAGACGGAGT-3' \\
\hline
\end{tabular}


Beijing, China) for $5 \mathrm{~min}$ at $4{ }^{\circ} \mathrm{C}$. Plasmid DNA was extracted using a plasmid mini kit (Qiagen) and sequenced using the T7 promoter by Invitrogen Company (Applied Biosystems model 3730; Shanghai Invitrogen BioTech Company, Shanghai, China).

After the 5' and 3' part of the sequence was obtained, a pair of forward primer (Primer 5, Table 1) and reverse primer (Primer 6, Table 1) was designed so that the full length CDNA of the gene could be obtained. RT-PCR conditions were: initial denaturation at $95^{\circ} \mathrm{C}$ for $5 \mathrm{~min}$, followed by 32 cycles at $95^{\circ} \mathrm{C}$ for $1 \mathrm{~min}, 61^{\circ} \mathrm{C}$ for 1.5 min and $72^{\circ} \mathrm{C}$ for 2 min $30 \mathrm{~s}$ with a final 10-min extension at $72^{\circ} \mathrm{C}$. The cDNA fragment obtained was ligated into a pGEMT-easy vector and sequenced. The NCBI database http://www.ncbi.nlm.nih.gov/BLAST/ was used to perform similarity searches and retrieve homologous sequences. The sequence analysis tools from the SWISS-PROT Internet server were used to process the data for the deduced protein sequences. Multiple sequence alignment was conducted using the DNAman software (version 4.13; Lynnon BioSoft, Quebec, Canada). The sequences included in our analysis for Sequence alignment and phylogenetic tree analysis were: Aedes aegypti: AY445078; Canis familiaris: XM_538698; Citrus clementina: FN552254; Culex pipiens pallens: HM443949; Culex quinquefasciatus: XM_001843334; Danio rerio: NM_001034983; Drosophila melanogaster: NM_058023; Gallus gallus: D16150; Homo sapiens: AF261088; Manduca sexta: AY032658; Mus musculus: AJ427344; Pan troglodytes: XM_001155874; Salmo salar: NM_001140230; Tribolium castaneum: XM_967008; Tribolium castaneum: XM_967008 and Vitis vinifera: XM_002263301.

\section{Real-time quantitative RT-PCR analysis}

$\beta$-actin (forward: Primer 9, Table 1; reverse: Primer 10, Table 1). To confirm the accuracy and reproducibility of real-time quantitative RT-PCR, the experiment was determined in three repeats within one LightCycler run. The results for IRE-BP 1 were normaliz $\beta$-actin (forward: Primer 9, Table 1; reverse: Primer 10, Table 1). To confirm the accuracy and reproducibility of real-time quantitative RT-PCR, the experiment was determined in three repeats within one LightCycler run. The results for IRE-BP 1 were normali $\beta$-actin (forward: Primer 9, Table 1; reverse: Primer 10, Table 1). To confirm the accuracy and reproducibility of real-time quantitative RT-PCR, the experiment was determined in three repeats within one LightCycler run. The results for IREBP 1 were normalized to the housekeeping $\beta$-actin gene. The threshold cycle $(\mathrm{Ct})$ values were used to quantify the target gene expression for each sample and amplification fold of IRE-BP 1 in Cr-IRE and in the susceptible strain of Culex pipiens pallens was calculated using the
$2^{-\Delta \Delta C t}$ method [22]. The real-time PCR analysis was repeated three times with independent samples.

\section{Semi-quantitative RT-PCR analysis of different life cycle} RT-PCR was also done with samples isolated from $\mathrm{Cr}$ IRE strain egg, 1st, 2nd, 3rd and 4th instar larvae, pupa and female adult mosquitoes to confirm the expression levels at each developmental stage using the primers described above. Mosquito $\beta$-actin gene cDNA was amplified by PCR using the forward primer (Primer 11, Table 1), and the reverse primer (Primer 12, Table 1).

The PCR conditions were: $95^{\circ} \mathrm{C}$ for $5 \mathrm{~min}$ followed by 25 cycles of $95^{\circ} \mathrm{C}$ for $40 \mathrm{~s}, 53^{\circ} \mathrm{C}$ for $40 \mathrm{~s}, 72^{\circ} \mathrm{C}$ for $1 \mathrm{~min}$ with a final 10 -min extension at $72^{\circ} \mathrm{C}$. The IRE-BP 1 and $\beta$-actin gene PCR products were resolved by electrophoresis on $1 \%$ agarose gels. Gels were photographed using Molecular Analyst 1.4.1 (Bio-Rad, Hercules, USA) and the images were analyzed by using BandScan 5.1 software. The magnitude of IRE-BP 1 expression in $\mathrm{Cr}$ IRE strain compared to the cypermethrin sensitive strain was calculated by the following formula: (RL/Rb)/(SL/ $\mathrm{Sb}) . \mathrm{RL}$ is the band intensity of Cr-IRE strain IRE-BP 1, $\mathrm{Rb}$ is the band intensity of Cr-IRE strain $\beta$-actin, SL is the band intensity of susceptible strain IRE-BP 1 and $\mathrm{Sb}$ is the band intensity of susceptible strain $\beta$-actin.

\section{Construction of the expression vector}

The entire coding region of IRE-BP 1 was amplified by PCR using the specific primers designed. The reverse primer was designed to remove the original stop codon and maintained the reading frame through the DNA encoding the $\mathrm{C}$-terminal peptide. The forward primer: (Primer 13, Table 1), and the reverse primer: (Primer 14, Table 1). The PCR conditions were: $95^{\circ} \mathrm{C}$ for $5 \mathrm{~min}$, followed by 32 cycles at $95^{\circ} \mathrm{C}$ for $1 \mathrm{~min}, 61^{\circ} \mathrm{C}$ for 1.5 min and $72^{\circ} \mathrm{C}$ for 2 min $30 \mathrm{~s}$ with a final 10-min extension at $72^{\circ} \mathrm{C}$. The PCR product was purified from the gel following electrophoresis using a quick Gel extraction kit (Qiagen). The purified PCR product was ligated with T4 DNA ligase to the pIB/V5-His-TOPO vector (Invitrogen, Carlsbad, USA), and the ligation reaction solution was transformed into TOP10 E. coli competent cells (Invitrogen). Positive clones were identified by restriction analysis of recombinants with NotI and BamHI, and by PCR with specific primers and vector primers. The accuracy of the expression plasmid $\mathrm{pIB} /$ V5-His-TOPO IRE-BP 1 was further verified by sequencing.

\section{Cell culture and stable transfection}

A. albopictus mosquito C6/36 cells were obtained from the China Center for Type Culture Collection (Wuhan, China). Cells were maintained in EMEM medium supplemented with $10 \%(\mathrm{~V} / \mathrm{V})$ fetal bovine serum (FBS, 
Sigma), $100 \mathrm{IU} / \mathrm{ml}$ penicillin and $100 \mu \mathrm{g} / \mathrm{ml}$ streptomycin (Invitrogen). The cells were grown in a $5 \% \mathrm{CO}_{2}$ humidified incubator at $28^{\circ} \mathrm{C}$ and were plated in a sixwell culture plate prior to transfection. When the cells were at $50-60 \%$ confluence, they were transfected using Cellfectin (Invitrogen) according to the manufacturer's instructions. Briefly, for each well, $2 \mu \mathrm{g}$ DNA was added to $100 \mu \mathrm{l}$ serum-free EMEM medium, then separately, 5 $\mu \mathrm{l}$ Cellfectin reagent was added to $100 \mu \mathrm{l}$ serum-free medium, then the two solutions were combined, mixed gently, and incubated at room temperature for $30 \mathrm{~min}$. Subsequently, $0.8 \mathrm{ml}$ of serum-free medium was added to this mixture and the entire mixture was layered on to cells after washing the cells with antibiotic-free medium. The cells were incubated with the transfection mixture for $24 \mathrm{~h}$ in a $5 \% \mathrm{CO}_{2}$ humidified incubator at $28^{\circ} \mathrm{C}$, and the transfection medium was then replaced with $2 \mathrm{ml}$ normal growth medium-containing serum. The cells were then incubated for an additional $48 \mathrm{~h}$ before being harvested for RT-PCR and Western blotting.

Once it had been confirmed that the cells were expressing the expected protein, stable expression cell lines were created according to the manufacturer's instructions. Briefly, a kill curve was performed to test the cell line for sensitivity to $14 \mu \mathrm{g} / \mathrm{ml}$ blasticidin, which can kill cells within one week. Forty-eight hours posttransfection, the transfection solution was removed and fresh medium without blasticidin was added. The cells were split at a 1:5 ratio and allowed to attach for 20 min before the selective medium was added. The medium was removed and replaced with medium containing $14 \mu \mathrm{g} / \mathrm{ml}$ blasticidin, and the cells were incubated at $28^{\circ}$ C. The selecting medium was replaced every 3-4 days until clones were observed. Eight days later, the medium was replaced with medium containing $7 \mu \mathrm{g} / \mathrm{ml}$ blasticidin. The resistant cell lines were isolated using a dilution method until only one colony was found in each well of a 96-well microtiter plate, after which the plate was incubated until the colony filled most area of the well. The cells were harvested and transferred to a 24well plate with $0.5 \mathrm{ml}$ fresh medium containing $7 \mu \mathrm{g} / \mathrm{ml}$ blasticidin, then the clone was expanded in 12-and 6well plates, and finally a T-25 flask. The cells were analyzed for expression using RT-PCR and Western blotting.

\section{Isolation of total RNA and RT-PCR analysis of the specific IRE-BP 1 transcript}

Total RNA was isolated from transfected cells by using Trizol reagent (Invitrogen) according to the manufacturer's protocol. Five micrograms of isolated total RNA from each sample was used as a template for firststrand cDNA synthesis. The cDNA was synthesized at $70^{\circ} \mathrm{C}$ for $5 \mathrm{~min}$, and $0^{\circ} \mathrm{C}$ for $5 \mathrm{~min}$, then $37^{\circ} \mathrm{C}$ for $1.5 \mathrm{~h}$ with a random primer using Avian myeloblastosis virus (AMV) reverse transcriptase ( $\mathrm{TaKaRa})$. The reverse transcriptase was then inactivated at $99^{\circ} \mathrm{C}$ for $5 \mathrm{~min}$. PCR amplification of the IRE-BP 1 gene was performed with the forward gene-specific primer (Primer 15, Table 1) and the reverse vector primer ((Primer 16, Table 1) for confirmation of transcriptional expression. The primers used for $\beta$-actin PCR amplification were: forward (Primer 17, Table 1) and reverse (Primer 18, Table 1). One microliter of the $\mathrm{RT}$ reaction product was used as the template for routine PCR. The following cycling parameters were used: $95^{\circ} \mathrm{C}$ for $5 \mathrm{~min}$ followed by 25 cycles of $95^{\circ} \mathrm{C}$ for $1 \mathrm{~min}, 60^{\circ} \mathrm{C}$ for $90 \mathrm{~s}$ and $72^{\circ} \mathrm{C}$ for $2.5 \mathrm{~min}$, followed by a final extension step of $72^{\circ} \mathrm{C}$ for $10 \mathrm{~min}$.

\section{Western blot analysis}

Protein was extracted from transfected cells by KEYGEN Total Protein Extraction Kit (Nanjing, China) according to the manufacturer's instructions and concentrations were determined by BCA Protein Assay kit (Pierce, USA). Twenty micrograms of protein per lane was used for SDS-PAGE electrophoresis. The gels were run for $100 \mathrm{~min}$ at $100 \mathrm{~V}$ and protein was transferred to a PVDF membrane at $40 \mathrm{~V}$ for $30 \mathrm{~min}$ then blocked in TBST and 5\% non-fat dry milk for $2 \mathrm{~h}$. Detection was done with the diaminobenzidine (DAB) chromogenic kit (Boster BioTech Company, Wuhan, China) according to the manufacturer's instructions. The membrane was exposed in visible light for $10 \mathrm{~min}$, then washed with $\mathrm{ddH} 2 \mathrm{O}$ to terminate the reaction. Molecular weight was determined by comparison with molecular weight markers (Bio-Rad).

\section{${ }^{3} \mathrm{H}-\mathrm{TdR}$ incorporation}

C6/36 cells were kept in the presence of various concentrations of cypermethrin $(1,5,10,20,40,80,120,160$ and $200 \mu \mathrm{M})$ for $72 \mathrm{~h}$ before ${ }^{3} \mathrm{H}-\mathrm{TdR}$ incorporation. Eighteen hours before harvesting, 11Ci of ${ }^{3} \mathrm{H}-\mathrm{TdR}$ was added to the medium of each well. To harvest the cells, EMEM medium was discarded, and cells were washed three times with $0.05 \mathrm{M}$ PBS (pH 7.4), and detached from the microtiter wells by trypsinization. Detached C6/36 cells were harvested onto glass fiber filter paper using a mini-MASH II microharvesting device (Whittaker MA Bioproducts, Walkersville, MD) and ${ }^{3} \mathrm{H}-\mathrm{TdR}$ incorporated into $\mathrm{C} 6 / 36$ (cell associated ${ }^{3} \mathrm{H}-\mathrm{TdR}$ ) was determined using a Wallac 1414 (WALLAC, Finland) liquid scintillation counter according to the manufacturer's instructions. Relative viability (\%) was calculated as the ratio of ${ }^{3} \mathrm{H}-\mathrm{TdR}$ reduction in treated cells to that of control cells $(\mathrm{C} 6 / 36$ cells transfected with vector and null-transfected C6/36 cells). Each condition was performed in triplicate. 


\section{Statistical analysis}

The inhibitive effect $(\mathrm{E})$ of the cypermethrin on the cell viability was described by the equation: $E=\left(E_{\max }{ }^{*} \mathrm{C}\right) /$ $\left(\mathrm{EC}_{50}+\mathrm{C}\right)$. Horizontal axis is the concentration of cypermethrin, vertical axis is the inhibition rate; Emax is the concentration at which maximum effect is reached, while $\mathrm{EC}_{50}\left(50 \%\right.$ effective dose $\left.\left[\mathrm{ED}_{50}\right]\right)$ is the concentration at which $50 \%$ of the maximum effect is reached. The $95 \%$ confidence intervals were used to determine significant differences among different cells.

\section{Results}

\section{Cloning of IRE-BP 1 full length CDNA}

A fragment of the expected size (2706 bp) was cloned and sequenced. Then the full sequence was accessed by GenBank (Figure 1, 2, GenBank Accession No. HM443949). The longest open reading frame encoded 901 amino acids with a predicted molecular mass of $98.75 \mathrm{kDa}$. The predicted isoelectric point is 5.54 by ExPASy. Amino acid sequence alignment of IRE-BP 1 was conducted by ClustalW software in different species (Figure 3, 4, 5, 6, 7, 8). Phylogenetic relationships of IRE-BP 1 among $C x$. pipiens pallens and some other species showed IRE-BP 1 of $C x$. pipiens pallens has the highest homology with Culex quinquefasciatus IRE-BP 1 $\mathrm{g}$ (Figure 9). SMART showed there is a typical IRE-BP 1 domain found. SIGNAL P3.0 indicted there that no peptide sequence existed in the sequence.

\section{Real-time quantitative RT-PCR analysis}

The IRE-BP 1 exhibited 6.7-fold higher level of transcription in the Cr-IRE strain than in the susceptible strain. The results suggested that IRE-BP 1 expression was up-regulated in the Cr-IRE strain (Figure 10).

\section{Expression of IRE-BP 1 gene at various developmental stages in Cr-IRE and susceptible $C x$. pipiens pallens}

A 315-bp cDNA fragment was selectively amplified using the specific primers. The amount of amplified cDNA product was normalized by comparison with the amplification product of the $\beta$-actin gene from $C x$. pipiens pallens (204 bp). The maximal level of IRE-BP 1 mRNA was detected in adult female mosquito, followed by the 4th instar larvae and the pupa. In all of the developmental stages, Cr-IRE strain has 3-to 4-fold increase of IRE-BP 1 transcription compared to the susceptible strain (Figure 11).

\section{Transcription and expression of IRE-BP 1 in C6/36 cells}

A PCR product of the expected size, about $2760 \mathrm{bp}$, was observed only in cells that were transfected with the IRE-BP 1 gene (Figure 12A), confirming that IRE-BP 1 had been transcribed in the transfected cells. Western blot analysis using anti-His antibodies identified a protein of 109.4 kDa molecular weight in cells transfected with the IRE-BP 1 gene (Figure 12B), confirming the exogenous IRE-BP 1 was expressed in C6/36 cells successfully.

\section{Viability assay}

Expression of the IRE-BP 1 gene improved the viability of cypermethrin-treated C6/36 cells. The $\mathrm{EC}_{50}$ and $95 \%$ confidence intervals of null-transfected cells are 35.24 (31.88-40.17), the $\mathrm{EC}_{50}$ and $95 \%$ confidence intervals of vector-transfected cells are 42.31 (34.19-49.26), and the $\mathrm{EC}_{50}$ and $95 \%$ confidence intervals of IRE-BP 1 transfected cells are 101.34 (91.23-113.71). Obvious cell viability augmentation was observed in the IRE-BP 1 transfected C6/36 cells compared to null-transfected or vector-transfected cells (Figure 13).

\section{Discussion}

Insecticide resistance has become a serious public health problem, which limited the effectiveness of pest control and presented an obstacle to the control of vector borne diseases $[12,23,24]$. Here we report the characterization of one cypermethrin resistance associated gene of $C x$. pipiens pallens [25]. The writer reported insecticideresistance ribosomal protein L39 gene of Cx. pipiens pallens, while other researchers in the same laboratory identified several genes differentially expressed in cypermethrin-resistant strain of the mosquito previously [15,26-37]. Some of the candidate genes encode for enzymes such as chymotrypsin [30], trypsin [34], CYP450 [29], which are likely involved in more direct functions, e.g. oxidation of cypermethrin, others are likely more upstream factors, such as ribosomal protein L39 [25]. The predicted Culex pipiens pallens IRE-BP 1 protein has many characteristics common to the IRE-BP 1 family, and the $C x$. pipiens pallens IRE-BP 1 protein sequence shared $99.45 \%$ identity with that of $C x$. quinquefasiatus. These results strongly suggest that this protein is the IRE-BP 1 of $C x$. pipiens pallens.

We determined the expression profile of IRE-BP 1 mRNA during the mosquito life cycle. Our results demonstrated that the levels of IRE-BP 1 expression are developmentally regulated, and the expression was the highest in adult mosquitos.

IRE-BP binds to iron-responsive elements (IREs), which were first identified in the 5' UTR of ferritin mRNA and in the 3'UTR of transferrin receptor (TftR) mRNA. Binding of IRE-BP to IREs is regulated by the iron status of the cell. Iron starvation activates binding and thus represses ferritin mRNA translation and stabilizes TfR transcripts in vivo. The effect of changes in iron availability in vivo can be mimicked by alterations in the redox environment of IRE-BP in vitro. This observation has led to the suggestion that IRE-BP 
atggctggtcctaacccctttcaaaacttacagaaagagctgactgttaatggcgagtgtttccgttattttgatatttcttccttcgaa

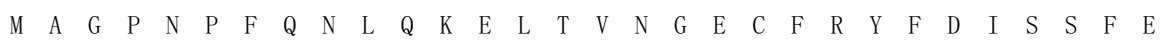
gagcttgccgaactcccatactcaatccgcgtcctactggagtcggcagtacgaaactgcgacaactttcaagtgcaggaaaaggatgtt $\begin{array}{lllllllllllllllllllllllllllllll}\text { E } & \text { L } & \text { A } & \text { E } & \text { L } & \text { P } & \text { Y } & \text { S } & \text { I } & \text { R } & \text { V } & \text { L } & \text { L } & \text { E } & \text { S } & \text { A } & \text { V } & \text { R } & \text { N } & \text { C } & \text { D } & \text { N } & \text { F } & \text { Q } & \text { V } & \text { Q } & \text { E } & \text { K } & \text { D } & \text { V }\end{array}$ cggggaatattaagttggaaaagcaccaagtctgagaaaacagacgtcgaattggagattccgttcaagcctgcgagagtaatccttcaa $\begin{array}{lllllllllllllllllllllllllllllll}R & G & I & L & S & W & K & S & T & K & S & E & K & T & D & V & E & L & E & I & P & F & K & P & A & R & V & I & L & Q\end{array}$ gattttacgggggtgcccgctgttgtcgacttcgccgcaatgagggatgcggtactcaaactaggtggcgacccagataagataaacccg $\begin{array}{lllllllllllllllllllllllllllllll}\text { D } & F & T & G & V & P & A & V & V & D & F & A & A & M & R & D & A & V & L & K & L & G & G & D & P & D & K & \text { I } & N & P\end{array}$ atttgtccttccgacctggtgatcgatcattcagttcaggtcgactttgctcgtactccettagccttgaacaaaaaccaagacttggag $\begin{array}{llllllllllllllllllllllllllllll}\text { I } & C & \text { P } & \text { S } & \text { D } & \text { L } & \text { V } & \text { I } & \text { D } & \text { H } & \text { S } & \text { V } & \text { Q } & \text { V } & \text { D } & \text { F } & \text { A } & \text { R } & \text { T } & \text { P } & \text { L } & \text { A } & \text { L } & \text { N } & \text { K } & \text { N } & \text { Q } & \text { D } & \text { L } & \text { E }\end{array}$ tttgagcgcaacaaggaacgattcacgtttctgaagtggggagccaaggctttcaacaacatgttgatcatccctccggggtcgggtatc $\begin{array}{llllllllllllllllllllllllllllll}F & E & R & N & K & E & R & F & T & F & L & K & W & G & A & K & A & F & N & N & M & L & I & I & P & P & G & S & G & I\end{array}$ gtacaccaggtgaacctggagtatttagctcgggttgtcttccaagacgatacaaaaagtaaggacggcagcaaaatattgtaccctgat $\begin{array}{lllllllllllllllllllllllllllllll}\mathrm{V} & \mathrm{H} & \mathrm{Q} & \mathrm{V} & \mathrm{N} & \mathrm{L} & \mathrm{E} & \mathrm{Y} & \mathrm{L} & \mathrm{A} & \mathrm{R} & \mathrm{V} & \mathrm{V} & \mathrm{F} & \mathrm{Q} & \mathrm{D} & \mathrm{D} & \mathrm{T} & \mathrm{K} & \mathrm{S} & \mathrm{K} & \mathrm{D} & \mathrm{G} & \mathrm{S} & \mathrm{K} & \mathrm{I} & \mathrm{L} & \mathrm{Y} & \mathrm{P} & \mathrm{D}\end{array}$ tctgtagtgggaacggactcccatactaccatgatcaacgggttgggagtggttggctggggtgtcggaggaatcgaagcggaagctgtt $\begin{array}{lllllllllllllllllllllllllllllll}S & V & V & G & T & D & S & H & T & T & M & I & N & G & L & G & V & V & G & W & G & V & G & G & I & E & A & E & A & V\end{array}$ atgctgggacaagcaatctccatgttacttcctgaggttatcggatacaagctagttggcaagcttaaccctctggttacgtcaacggat $\begin{array}{lllllllllllllllllllllllllllllll}M & L & G & Q & A & I & S & M & L & L & P & E & V & I & G & Y & K & L & V & G & K & L & N & P & L & V & T & S & T & D\end{array}$ ttggtgttgaccatcaccaagaatctgcgccagattggagtcgtcggaaagtttgttgaattcttcggacctggtgtcagcgagttatcg $\begin{array}{lllllllllllllllllllllllllllllll}\text { L } & V & L & T & I & T & K & N & L & R & Q & I & G & V & V & G & K & F & V & E & F & F & G & P & G & V & S & E & L & S\end{array}$ atcgcagatcgtgctacgatcagtaacatgtgtcctgagtatggtgcaaccgtgggatatttcccgatcgaccagaacgcgttggattat $\begin{array}{lllllllllllllllllllllllllllllll}\text { I } & A & D & R & A & T & I & S & N & M & C & P & E & Y & G & A & T & V & G & Y & F & P & I & D & Q & N & A & L & D & Y\end{array}$ ctccgacagacgaaccgtgccgaagataaggtccaggtcatcgaagcgtatttcaaagcaaccaaccaactacgaaacttctcagacgcg $\begin{array}{lllllllllllllllllllllllllllllll}\mathrm{L} & \mathrm{R} & \mathrm{Q} & \mathrm{T} & \mathrm{N} & \mathrm{R} & \mathrm{A} & \mathrm{E} & \mathrm{D} & \mathrm{K} & \mathrm{V} & \mathrm{Q} & \mathrm{V} & \mathrm{I} & \mathrm{E} & \mathrm{A} & \mathrm{Y} & \mathrm{F} & \mathrm{K} & \mathrm{A} & \mathrm{T} & \mathrm{N} & \mathrm{Q} & \mathrm{L} & \mathrm{R} & \mathrm{N} & \mathrm{F} & \mathrm{S} & \mathrm{D} & \mathrm{A}\end{array}$ tcgcaggatccagtgtacacacaagttatcgaactggacttaggaacggtcgtaactagtgtgagcgggccgaagcggcctcacgataga $\begin{array}{lllllllllllllllllllllllllllllll}S & Q & D & P & V & Y & T & Q & V & I & E & L & D & L & G & T & V & V & T & S & V & S & G & P & K & R & P & H & D & R\end{array}$ gtttctgtctccgacatgcagaaagattttcaagagtgtttgaccaacaaggtaggtttcaaaggctttgctatacccgacgcccagctt $\begin{array}{lllllllllllllllllllllllllllllll}\mathrm{V} & \mathrm{S} & \mathrm{V} & \mathrm{S} & \mathrm{D} & \mathrm{M} & \mathrm{Q} & \mathrm{K} & \mathrm{D} & \mathrm{F} & \mathrm{Q} & \mathrm{E} & \mathrm{C} & \mathrm{L} & \mathrm{T} & \mathrm{N} & \mathrm{K} & \mathrm{V} & \mathrm{G} & \mathrm{F} & \mathrm{K} & \mathrm{G} & \mathrm{F} & \mathrm{A} & \mathrm{I} & \mathrm{P} & \mathrm{D} & \mathrm{A} & \mathrm{Q} & \mathrm{L}\end{array}$ aagacagaaggatcattctcgtggacggatgggaacacttatagtctcaggcatggtagcgtggtcattgctgcgatcacctcttgcaca $\begin{array}{lllllllllllllllllllllllllllllll}K & T & E & G & S & F & S & W & T & D & G & N & T & Y & S & L & R & H & G & S & V & V & I & A & A & I & T & S & C & T\end{array}$ aacacgtccaacccatcagtcatgctaggcgctggactgttagccaaaaaggcagtagcgttggggcttaaagtggctccgtacataaag $\begin{array}{lllllllllllllllllllllllllllllll}N & T & S & N & P & S & V & M & L & G & A & G & L & L & A & K & K & A & V & A & L & G & L & K & V & A & P & Y & I & K\end{array}$ acttcgctcagtccttatagcggtgttgtcacctactatctaaaagagtctggcgtagtgcccgccctggaagagttaggatttcacgtt $\begin{array}{lllllllllllllllllllllllllllllll}T & S & L & S & P & Y & S & G & V & V & T & Y & Y & L & K & E & S & G & V & V & P & A & L & E & E & L & G & F & H & V\end{array}$ gtcgggtacggttgtatgacatgcattggcaactccggaccattggacgataacatcgcaaatacgatagaaaagaacaatctggtttgc $\begin{array}{lllllllllllllllllllllllllllllll}V & G & Y & G & C & M & T & C & I & G & N & S & G & P & L & D & D & N & I & A & N & T & I & E & K & N & N & L & V & C\end{array}$ tgcggagtactttctggaaaccgtaacttcgagggtcgtattcatccgaacactcgagcgaattatctagcttcgcctctgttagttatc $\begin{array}{lllllllllllllllllllllllllllllll}C & G & V & L & S & G & N & R & N & F & E & G & R & I & H & P & N & T & R & A & N & Y & L & A & S & P & L & L & V & \text { I }\end{array}$ gcctacgcattggcgggaaccgtcgacatagattttgaaaaagagcccattgggacaacgccagaaggtaacaatgtattccttcgggac $\begin{array}{lllllllllllllllllllllllllllllll}\text { A } & Y & A & L & A & G & T & V & D & \text { I } & \text { D } & \text { F } & \text { E } & \text { K } & \text { E } & \text { P } & \text { I } & G & \text { T } & \text { T } & \text { P } & \text { E } & G & \text { N } & \text { N } & \text { V } & \text { F } & \text { L } & \text { R } & \text { D }\end{array}$ atctggccgactagagctgagatacaagaagtggagaggcagcacgttattcctgccatgtttcgtgatgtctatgcaaaggtagaactc $\begin{array}{llllllllllllllllllllllllllllll}I & W & P & T & R & A & E & I & Q & E & V & E & R & Q & H & V & I & P & A & M & F & R & D & V & Y & A & K & V & E & L\end{array}$ ggcgcgagtagctggcaatctctaaacgctcccaccggaaaactgtacccatgggacaatgcctccacatatatcaagcatccgcctttc $\begin{array}{lllllllllllllllllllllllllllllll}G & A & S & S & W & Q & S & L & N & A & P & T & G & K & L & Y & P & W & D & N & A & S & T & Y & I & K & H & P & P & F\end{array}$
$-90$

$-180$ $-270$

$-360$

$-450$

$-540$

$-630$

$-720$

$-810$

$-900$

$-990$

$-1080$

$-1170$

$-1260$

$-1350$

$-1440$

$-1530$

$-1620$

$-1710$

$-1800$

$-1890$

$-1980$

Figure 1 CDNA sequence and deduced amino acid sequence of IRE-BP 1. CDNA sequence and deduced amino acid sequence of IRE-BP 1. Stars denote the stop codon TAA. GenBank Accession No. HM443949.

activity is regulated post-translationally by the reversible oxidation-reduction of cysteinyl sulthydryl groups important for the interaction of IRE-BP and IREs.

In cells that are iron-depleted, the Fe-S cluster of cytosolic aconitase is disrupted, resulting in a loss of aconitase activity and the exposure of the RNA-binding site so that, as the IRE-BP, it can bind with high affinity to the IRE [19]. In the presence of adequate iron, the [4Fe-4S] cluster is reassembled, enzyme activity is regained, and RNA binding is lost. The binding of the 


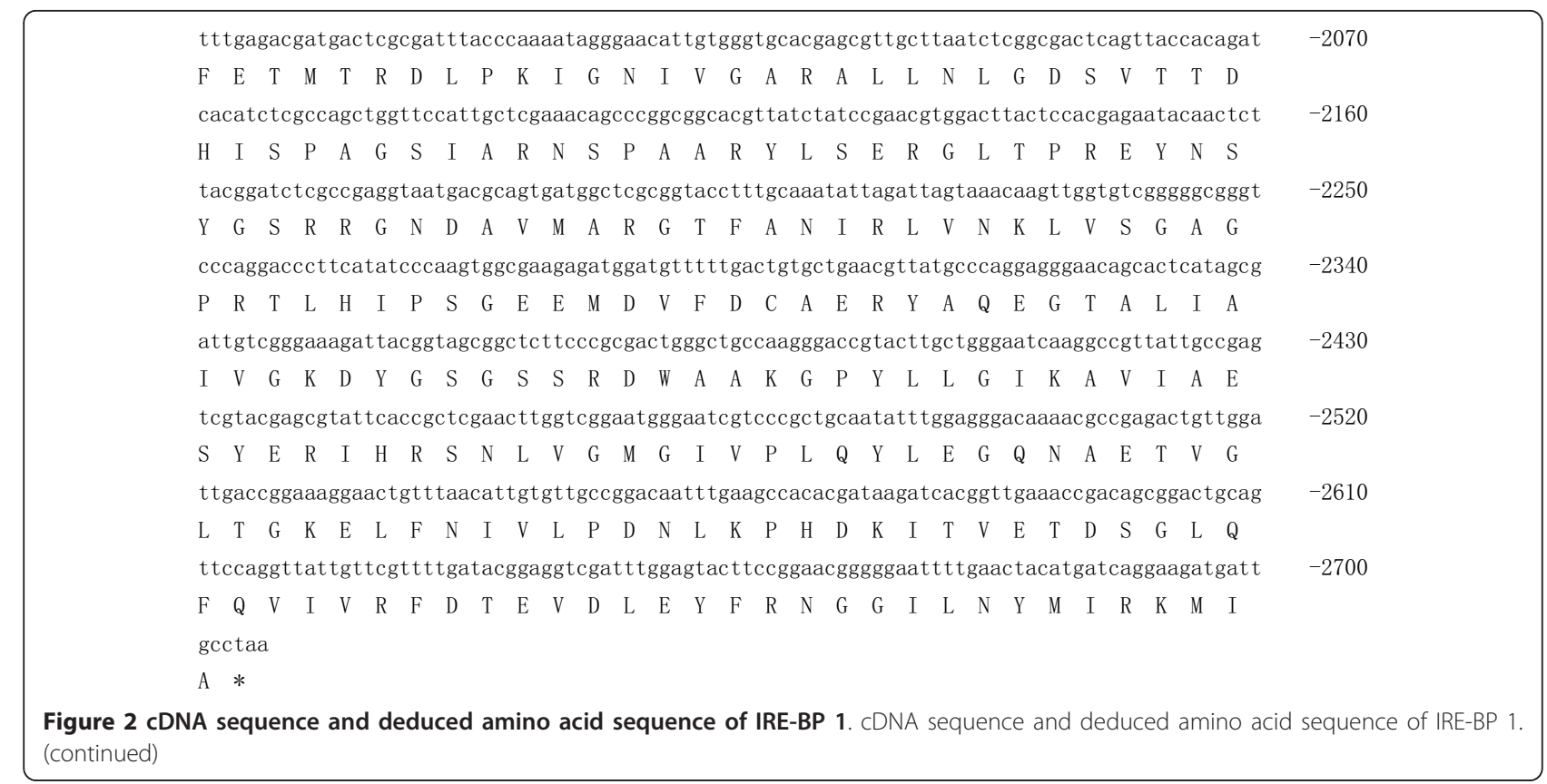

IRE-BP to the IRE found in the 5 ' untranslated region of transcripts for ferritin or the erythroid form of 5-aminolevulinate synthase down-regulates protein synthesis, most likely through an inhibition of translation initiation [38]. In the case of transferrin receptor regulation, five
IREs are found within the 3' untranslated region of the transcript and their interaction with the IRE-BP results in a stimulation of transferrin receptor synthesis by inhibiting degradation of the mRNA [9]. The dynamic properties of the Fe-S cluster in the IRE-BP/cytosolic
Aedes_aegypti.seq Canis familiaris.seq

Citrus_clementin.seq

Cx.pipiens.seq

Cx.quin.seq

Danio_rerio.seq

Drosophila.seq

Gallus_gallus.seq

Homo_sapiens.seq

Manduca.seq

Mus_musculus.sed

Pan troglodytes.seq

Salmo_salar.seq

Vitis_vinifera.seq

Conseñsus
...... MAGTNPFQNLQKELN . . VNGE TF HYF D I ASF . . EEF KELPYS IRVLLESAVRNCDNFOVLEKDVRGILSWKA $\ldots \ldots \ldots$ MSNPF AHL IEPLD . . P AQPGKKF FNLNKL K DSRYERL PF S IRVLLE A. I IRNCDQF LVKKND IENILNUNV $\ldots \ldots \ldots$ MATENPF KS ILKTLQRP DGGEF GKYYSL P ALN DPR I GKLPYS IKILLES A IRNCDEF QVKSKDVEKI IDWET ....... MAGPNPF QNLQKELT . .VNGECFRYFD ISSF . .EELAELPYS IRVLLES AVRNCDNF QVQEKDVRGILSWKS $\ldots \ldots \ldots$ MAGPNPF QNLQKELT . . VNGECFRYF D ISSF . .EELAELPYS IRVLLES AVRNCDNFQVLEKDVRGILSWKS $\ldots \ldots \ldots$ MTNPY AHTVE PLD . . PQKP D HKF FNLRKL K D PRYEQL PF S IRVLLES AVRNCDQF LVKQDDVEKILNWKV $\ldots \ldots$ MSGSG MNPF AQF QESFT . . QDGNVYKYF DLPSID . SKYESLPF S IRVLLES AVRNCDNF HVLE KDVQS IL GWTP $\ldots \ldots \ldots$ MSNPFVQIVEPLD $\ldots$ AKEPVKKF FNLSKLE DVRY ARLPFS IRVLLE A I IRNCDEFLVKKQDVENILNWKV

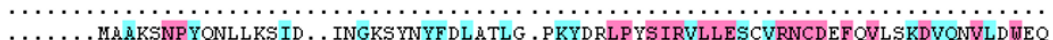
$\ldots \ldots \ldots \ldots$ MKNP F AHL AEPLD . A.AQP GKRF FNLNKLE DSRYGRLPF S IRVLLE A. MVRNCDEFLVKKND IENILNWNV

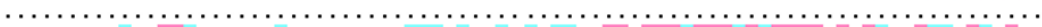
MCERGRKST M MSNPF AHIVE ALD . . PNNP D HKF YNLSKL G DPRYDRL PF S IRVLLES AVRNCDGF LVKRSDVES ILNWKR $\ldots \ldots \ldots$ ASSNPF AS ILKTLEKP AGGEF GKYYSLP ALG DPR IDRLPYS IRILLESA I RNCDEFQVKAKDVEKI IDUEN

68
68
72
68
68
68
71
68
0
70
68
0
78
71

\section{TKSVKTD TELËIPFKP ARV ILQDF TGVP AVVDF A AMRD AV L KL GGD PD KINP ICPSDLVIDHSVQVDF ÄRAPD AL TKNQD} MQHKN I . . . . EVPFKP ARV IL QDF TGVP AVVDF A AMRD AV KKL GGDPEKINP ICP ADLV ID HS IQVDFNRRTDSLQKNQ

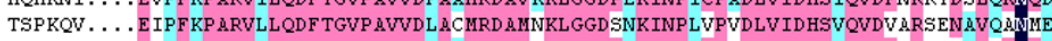
TKSEKTDVELE IPF KP ARV ILQDF TGVP AVVDF A AMRD AVL KL GGDP D KINP ICPSDLV ID HSVQVDF ARTPL ALNKNQ

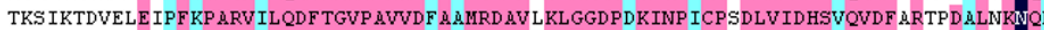
TQSQTV . . . EVPFRP ARV ILQDF TGVP AVVDF A AMRD AV KKLQGDPE KINPVCP ADLVID HS IQVDFNRKSDSL QKNO SLKQE TS . DVEVSF KP ARV ILQDF TGVP AVVDF A AMRD AV REL GGNP E KINP ICP ADLV ID HSVQVDFVRSSD AL TKNE MQHKNV . . . EVPF KP ARV ILQDF T GVP AVVD F A AMRD AV KKLGGDP E KINP ICP AD LV ID HS IQVD FNRRSDSLQKNQ

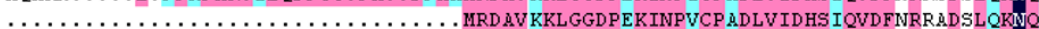
NQAVE G. . GVE I ÄF KP ARV ILODL TGVP AVVDF A AMRD AV KDL GGDPOKINP ICP ADLV IDHSVOVDF ARTPD ALNKNOE MQHKN I . . . EVPF KP ARV ILQDF T GVP AVVDF A A MRD AV KKL G GNP E KINPVCP AD LV ID HS IQVD FNRRADSLQKNQ MQHKNI $\ldots \ldots$ EVPFKP ARV ILQDF TGVP AVVDF AAMRD AV KKLGGNPE KINPVCP ADLVIDHS IQVDFNRRADSLQKNQD

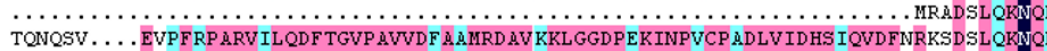
SSPKQV . . E E IPF KP ARVLLQDF TGVP AVVDL ACMRD AMNKL GGDSNKINPLVPVDLVIDHSVQVDVAGSENAVQAMNE

148
144
148
148
148
144
150
144
45
148
144
11
154
147

Figure 3 Amino acid sequence alignment of IRE-BP 1 in different species. Amino acid sequence alignment of IRE-BP 1 in different species. Abbreviations and GenBank Accession Numbers: Aedes aegypti: AY445078; Canis familiaris: XM_538698; Citrus clementina: FN552254; Culex pipiens pallens: HM443949; Culex quinquefasciatus: XM_001843334; Danio rerio: NM_001034983; Drosophila melanogaster: NM_058023; Gallus gallus: D16150; Homo sapiens: AF261088; Manduca sexta: AY032658; Mus musculus: AJ427344; Pan troglodytes: XM_001155874; Salmo salar: NM_001140230; Vitis vinifera: XM_002263301. 


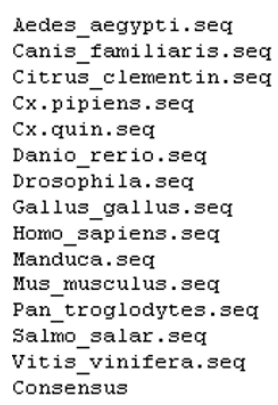

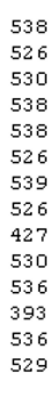

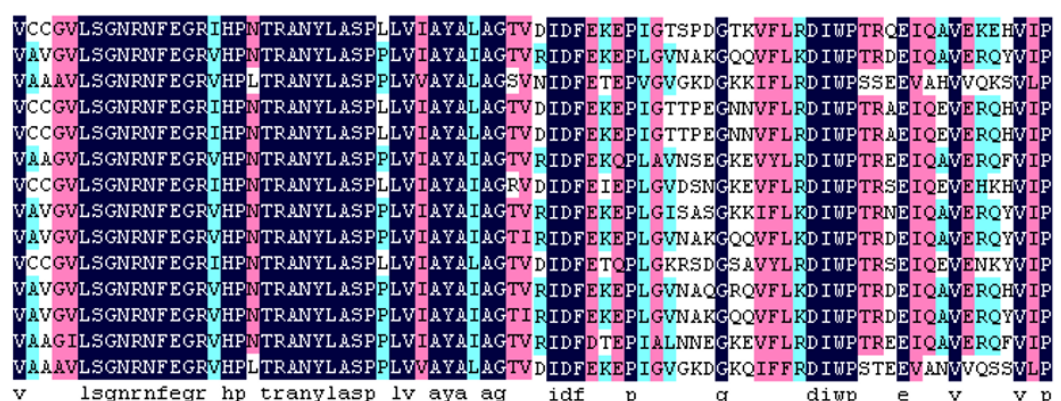

Figure 6 Amino acid sequence alignment of IRE-BP 1. Amino acid sequence alignment of IRE-BP 1 in different species. (continued)

we do not have enough information to pinpoint the exact role of IRE-BP 1 in cypermethrin resistance, our results suggest that IRE-BP 1 is a good candidate for future studies of pyrethroid resistance.

The IRE-BP 1 family spans both vertebrates and invertebrates. It includes serum IRE-BP 1, ovo IRE-BP 1, lactoferrin, melano IRE-BP 1, inhibitor of carbonic anhydrase, saxiphilin, the major yolk protein in sea urchins, the crayfish protein, pacifastin, and a protein from green algae. Most (but not all) contain two domains of around 340 residues, thought to have evolved from an ancient duplication event. For serum IRE-BP 1, ovo IRE-BP 1 and lactoferrin each of the duplicated lobes binds one atom of Fe (III) and one
Aedes_aegypti.seq

Canis familiaris.seq

Citrus clementin.seq

Cx.pipiens.seq

Cx.quin.seq

Danio_rerio.seq

Drosophila.seq

Gallus_gallus.seq

Homo_sapiens.seq

Manduca.seq

Mus musculus.seq

Pan troglodytes.seg

Salmo salar.seq

Vitis_vinifera.seq

Consensus

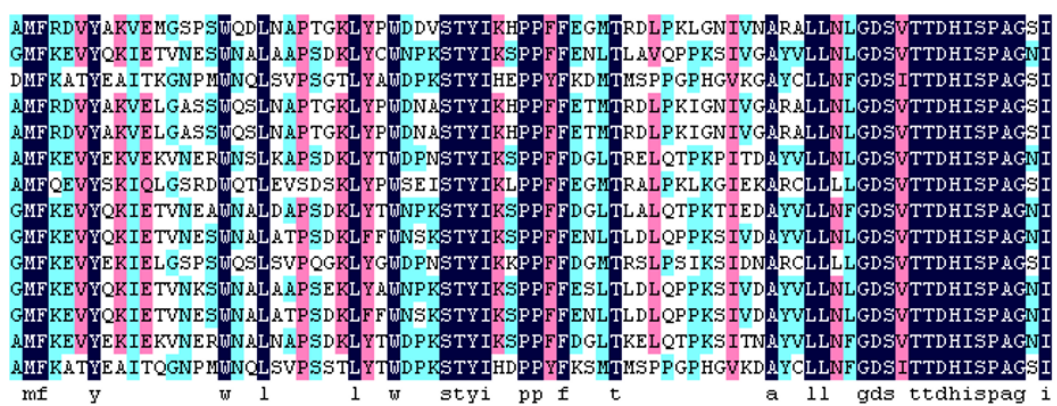

698

686

690

698

698

699

587

690

553

696

689

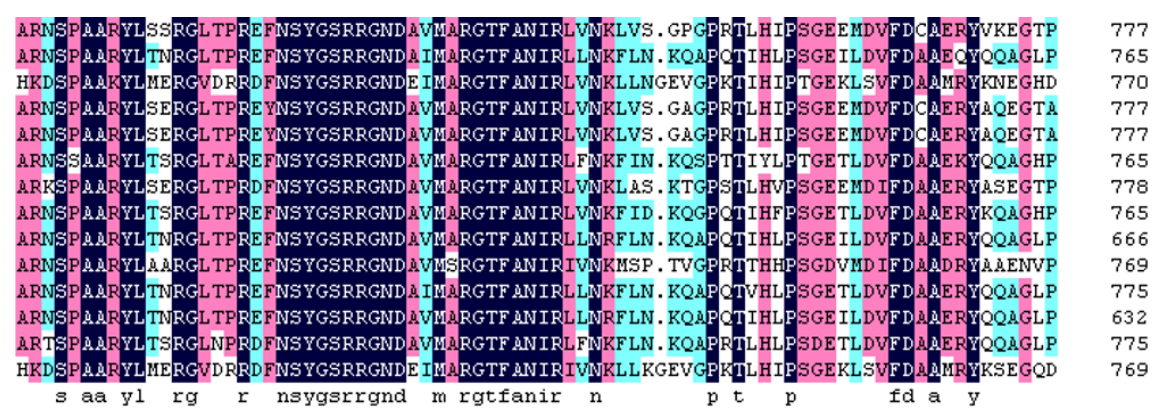

Figure 7 Amino acid sequence alignment of IRE-BP 1. Amino acid sequence alignment of IRE-BP 1 in different species. (continued) 

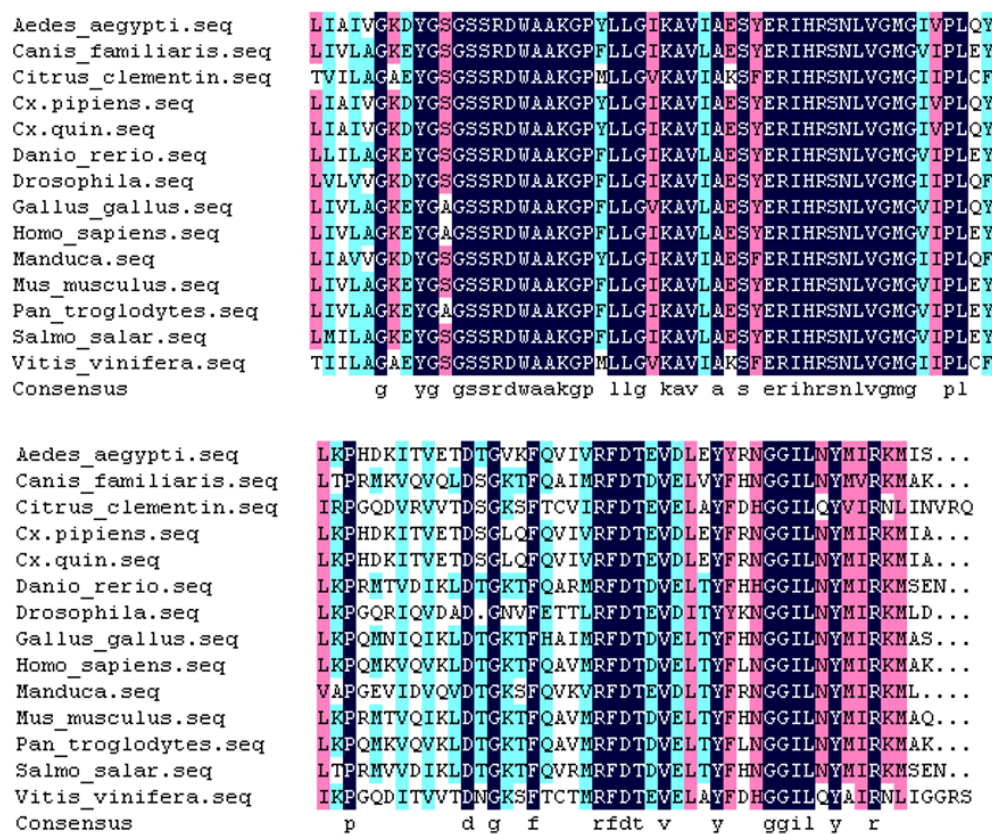

Figure 8 Amino acid sequence alignment of IRE-BP 1. Amino acid sequence alignment of IRE-BP 1 in different species. (continued)

carbonate anion. With a few notable exceptions each iron atom is coordinated to four conserved amino acid residues: an aspartic acid, two tyrosines, and a histidine, while anion binding is associated with an arginine and a threonine in close proximity. These six residues in each

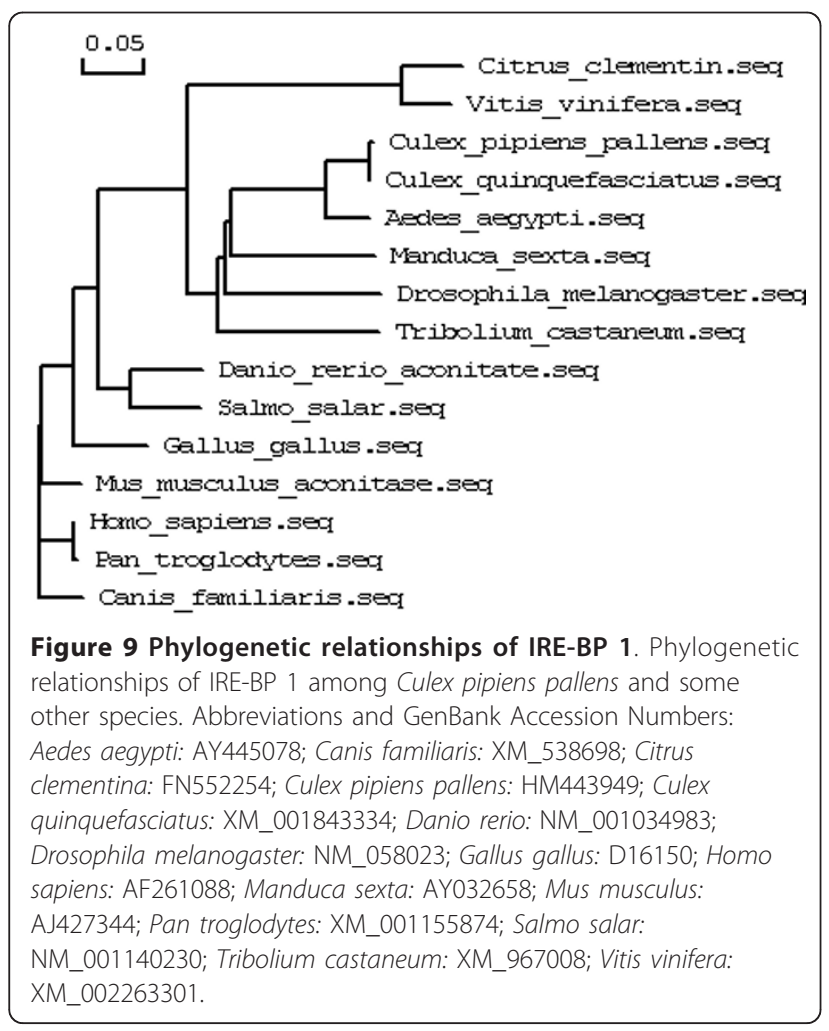

lobe were examined for their evolutionary conservation in the homologous $\mathrm{N}$ - and C-lobes of 82 complete IREBP 1 sequences from 61 different species. Of the ligands in the $\mathrm{N}$-lobe, the histidine ligand shows the most

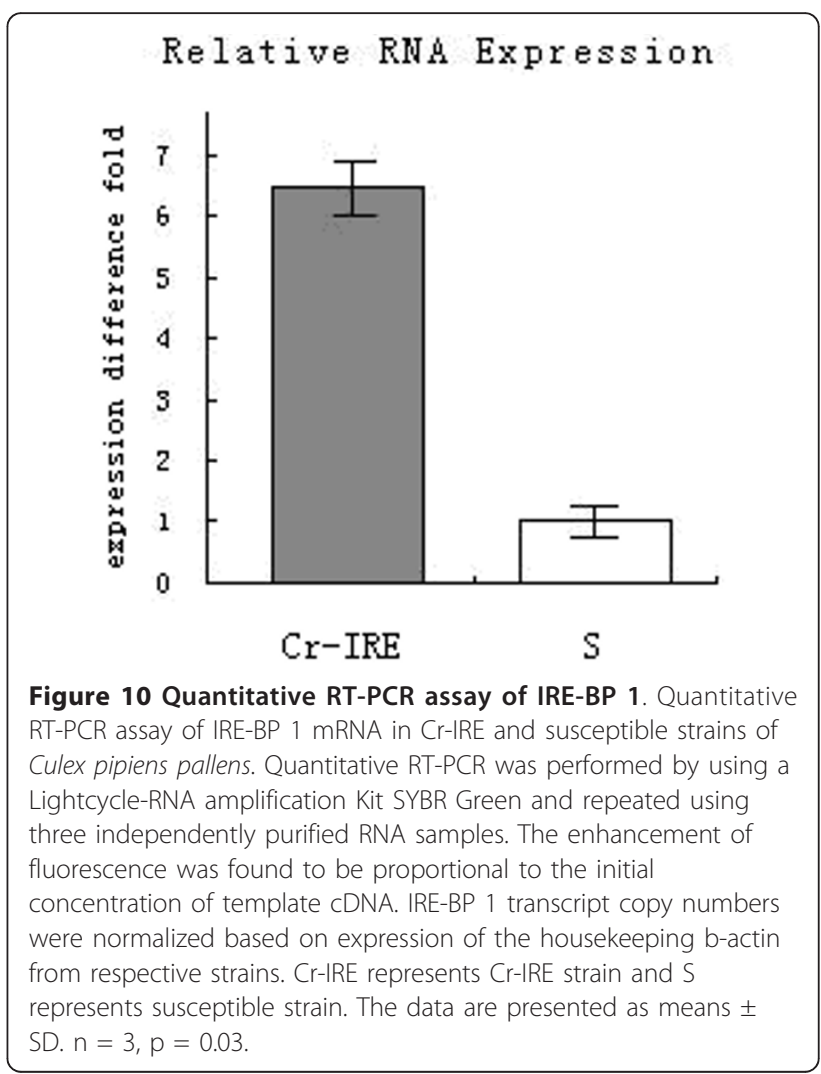




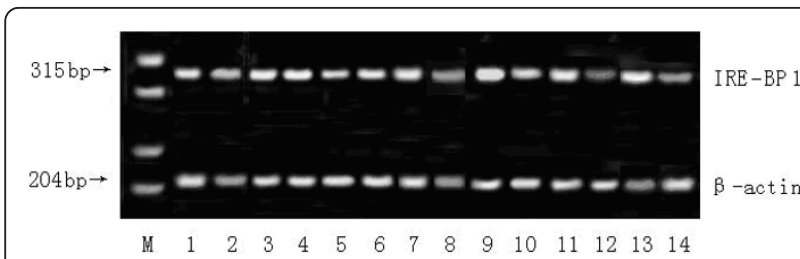

Figure 11 Semi-quantitative RT-PCR. Semi-quantitative RT-PCR of each life stage showed the relative amount of amplified transcripts of IRE-BP 1 (panel 1) in comparison with amplified mosquito b-actin gene transcripts (panel 2). M, marker; 1, Cr-IRE strain egg; 2, susceptible strain egg; 3, Cr-IRE strain 1st larvae; 4, susceptible strain 1st larvae; 5, Cr-IRE strain 2nd larvae; 6, susceptible strain 2nd larvae; 7, Cr-IRE strain 3rd larvae; 8, susceptible strain 3rd larvae; 9, Cr-IRE strain 4th larvae; 10, susceptible strain 4th larvae; 11, Cr-IRE strain pupa; 12, susceptible strain pupa; 11, Cr-IRE strain pupa; 12, susceptible strain pupa; 13, CrIRE strain female mosquito; 14 , susceptible strain female mosquito.

variability in sequence. Also, of note, four of the twelve insect IRE-BP $1 \mathrm{~s}$ have glutamic acid substituted for aspartic acid in the N-lobe (as seen in the bacterial ferric binding proteins). In addition, there is a wide spread substitution of lysine for the anion binding arginine in the N-lobe in many organisms including all of the fish, the sea squirt and many of the unusual family members i.e., saxiphilin and the green alga protein. It is hoped that this short analysis will provide the impetus to establish the true function of some of the TF family members that clearly lack the ability to bind iron in one or both lobes and additionally clarify the evolutionary history of this important family of proteins.

\section{Conclusions}

In summary, we have cloned the first IRE-BP 1 gene known from $C x$. pipiens pallens. Based on the characteristics of the gene, it is a member of the IRE-BP 1 family. The data in the present study suggests that IRE-BP 1 may confer some cypermethrin resistance in mosquitoes. Research carried out to date has provided a basis for further studies on the gene function associated with

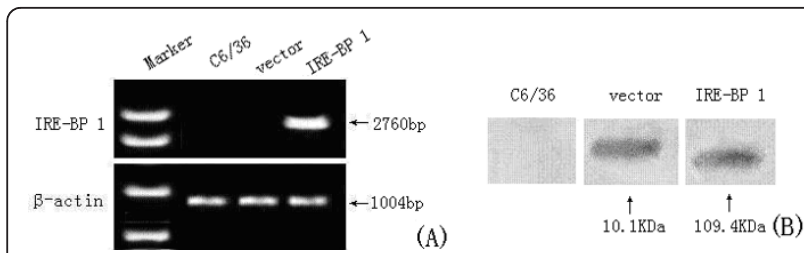

Figure 12 Effects of expression and transcripts of IRE-BP 1 in cells. (A) RT-PCR analysis of IRE-BP 1 mRNA in mosquito cells using forward primer of IRE-BP 1 and reverse primer of vector. The production of the transcripts was detected in cells transfected with IRE-BP 1 (lane 2); No signal was detected either in normal cells (lane 3) or in cells transfected with vector (lane 1). (B). Western blot analysis. Expression of IRE-BP 1 was detected in cells transfected with IRE-BP 1 (lane 3), expression of vector protein was detected in cells transfected with vector (lane 2), no signal was detected in normal cells (lane 1).

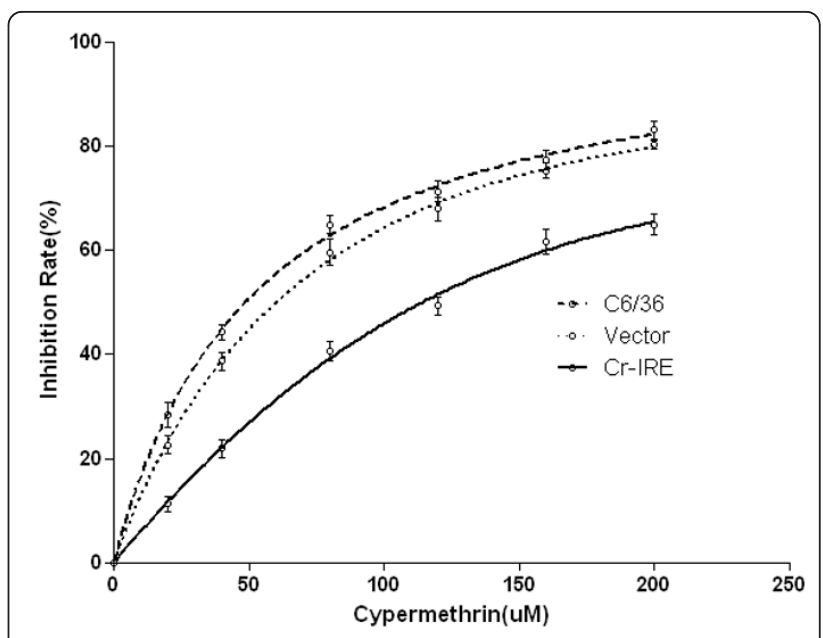

Figure 13 Inhibitive effect of cypermethrin on cell viability. The cultured cells were treated with different concentration of cypermethrin and incubated for $72 \mathrm{~h}$. The inhibitive effect(E)of the cypermethrin on the cell viability was described by the equation: $\mathrm{E}$ $=\left(\mathrm{Emax}^{*} \mathrm{C}\right) /\left(\mathrm{EC}_{50}+\mathrm{C}\right)$.

insecticide resistance, which will improve our understanding of the molecular basis of IRE-BP 1 mediated resistance in Cx. pipiens pallens.

\section{Acknowledgements}

The work was supported by grants from the Office of Education Research Fund of Shandong Province (No. J09LF04 to Tan Wenbin), the natural science foundation of Shandong Province (No. ZR2011HL004 to Tan Wenbin), Jining Science and Technology Research Fund (Tan Wenbin, 2009) and Jining outstanding youth fund project of scientific research innovation (Tan Wenbin, 2010).

\section{Author details}

'Department of Pathogenic Biology, Jining Medical University, Jining, Shandong Province, 272067, PR China. ${ }^{2}$ Shandong Institute of Parasitic Diseases, A grand key laboratory of health department, Jining, Shandong Province, 272013, PR China. ${ }^{3}$ Department of Pathogenic Biology, Nanjing Medical University; Key Laboratory of Modern Pathogenic Biology of Jiangsu Province, Nanjing, Jiangsu Province, 210029, PR China.

\section{Authors' contributions}

Wenbin Tan coordinated and carried out the whole experiment and manuscript writing, Xiao Wang participated in the cell culture and data analysis. Peng Cheng participated in the sequence alignment. Lijuan Liu and Haifang Wang participated in the sequence alignment. Maoqing Gong participated in the RT-PCR and RACE experiment. Xin Quan participated in the ${ }^{3} \mathrm{H}-\mathrm{TdR}$ experiment. Honggang Gao participated in the Real-time quantitative RT-PCR analysis. Changliang Zhu participated in the design of the study and performed the statistical analysis.

All authors read and approved the final manuscript.

\section{Competing interests}

The authors declare that they have no competing interests.

Received: 30 August 2011 Accepted: 10 November 2011 Published: 10 November 2011

\section{References}

1. Wood OR, Hanrahan S, Coetzee M, Koekemoer LL, Brooke BD: Cuticle thickening associated with pyrethroid resistance in the major malaria vector Anopheles funestus. Parasit Vectors 2010, 3:67. 
2. Pedersen EM, Stolk WA, Laney SJ, Michael E: The role of monitoring mosquito infection in the Global Programme to Eliminate Lymphatic Filariasis. Trends in parasitology 2009, 25:319-327.

3. Salvemini M, Mauro U, Lombardo F, Milano A, Zazzaro V, Arca B, Polito LC, Saccone G: Genomic organization and splicing evolution of the doublesex gene a Drosophila regulator of sexual differentiation in the dengue and yellow fever mosquito Aedes aegypti. BMC Evol Biol 2011, 11:41.

4. Wu X, Hong H, Yue J, Wu Y, Li X: Inhibitory effect of small interfering RNA on dengue virus replication in mosquito cells. Virol J 2010, 7:270.

5. Dutta P, Khan SA, Khan AM, Borah J, Sarmah CK, Mahanta J: The effect of insecticide-treated mosquito nets (ITMNs) on Japanese encephalitis virus seroconversion in pigs and humans. Am J Trop Med Hyg 2011, 84:466-472.

6. Itokawa K, Komagata O, Kasai S, Masada M, Tomita T: Cis-acting mutation and duplication: History of molecular evolution in a P450 haplotype responsible for insecticide resistance in Culex quinquefasciatus. Insect Biochem Mol Biol 2011, 41:503-512.

7. Kumar K, Sharma AK, Kumar S, Patel S, Sarkar M, Chauhan LS: Multiple insecticide resistance/susceptibility status of Culex quinquefasciatus principal vector of bancroftian filariasis from filaria endemic areas of northern India. Asian Pac J Trop Med 2011, 4:426-429.

8. Li T, Liu N: Inheritance of permethrin resistance in Culex quinquefasciatus. J Med Entomol 2010, 47:1127-1134.

9. Wang J, Pantopoulos K: Regulation of cellular iron metabolism. Biochem J 2011, 434:365-381.

10. Weill M, Duron O, Labbe P, Berthomieu A, Raymond M: Insecticide resistance in the mosquito Culex pipiens. Med Sci (Paris) 2003, 19:1190-1192.

11. Schellenberg JA, Minja H, Mponda H, Kikumbih N, Mushi A: Re-treatment of mosquito nets with insecticide. Trans R Soc Trop Med Hyg 2002, 96:368-369.

12. Darriet Frédéric, Marcombe Sébastien, Etienne Manuel, Yébakima André, Agnew Philip, Yp-Tcha Marie-Michelle, Corbel Vincent: Field evaluation of pyriproxyfen and spinosad mixture for the control of insecticide resistant Aedes aegypti in Martinique (French West Indies). Parasit Vectors 2010, 3:88.

13. Pemba DF, Bandason E, Namangale J: Comparison of deltamethrin as indoor residual spray or on insecticide treated nets for mosquito control in Lake Chilwa, Malawi. Med J 2008, 20:86-89.

14. Pennetier Cédric, Chabi Joseph, Martin Thibaud, Chandre Fabrice, Rogier Christophe, Hougard Jean-Marc, Pages Frédéric: New protective battle-dress impregnated against mosquito vector bites. Parasit Vectors 2010, 3:81.

15. Chen L, Zhong D, Zhang D, Shi L, Zhou G, Gong M, Zhou H, Sun Y, Ma L, He J, Hong S, Zhou D, Xiong C, Chen C, Zou P, Zhu C, Yan G: Molecular ecology of pyrethroid knockdown resistance in Culex pipiens pallens mosquitoes. PloS One 2010, 5:e11681.

16. Mugni H, Demetrio P, Bulus G, Ronco A, Bonetto C: Effect of aquatic vegetation on the persistence of cypermethrin toxicity in water. Bull Environ Contam Toxicol 2011, 86:27.

17. Al-Sarar AS, Al-Hafiz AM, Bakr YA, Bayoumi AE, Hussein HI: Effects of space spray application methods on fenitrothion efficacy and development of resistance in Culex pipiens. J Am Mosq Control Assoc 2011, 27:129-134.

18. Wang $H$, Cheng $P$, Zhen $T$, Jiang $H$, Wang $H$, Sun $C$, Zhao $Y$, Wang $X$ : Tentative study on resistance development and cross-resistance of DDVP-resistant Culex pipiens pallens. Parasitoses and Infectious Diseases 2005, 3:11-13.

19. Popovic Z, Templeton DM: Inhibition of an iron-responsive element/iron regulatory protein-1 complex by ATP binding and hydrolysis. FEBS $J$ 2007, 274:3108-3119.

20. Harigae $\mathrm{H}$ : Recent progress in iron metabolism and iron-related anemia. Rinsho Byori 2010, 58:1211-1218.

21. Saitoh Y, Ogawa A, Hori T, Kunita R, Mizuno S: Identification and localization of two genes on the chicken $Z$ chromosome: implication of evolutionary conservation of the $\mathbf{Z}$ chromosome among avian species. Chromosome Res 1993, 1:239-251.

22. Livak KJ, Schmittgen TD: Analysis of relative gene expression data using real-time quantitative PCR and the 2(-Delta Delta C(T)) Method. Methods 2001, 4:402-408

23. Annabel FVHoward, N'Guessan Raphael, Constantianus JMKoenraadt Asidi Alex, Farenhorst Marit, Akogbéto Martin, Thomas BMatthew,
Knols GJBart, Takken Willem: The entomopathogenic fungus Beauveria bassiana reduces instantaneous blood feeding in wild multi-insecticideresistant Culex quinquefasciatus mosquitoes in Benin, West Africa. Parasit Vectors 2010, 3:87.

24. Okumu FO, Madumla EP, John AN, Lwetoijera DW, Sumaye RD: Attracting, trapping and killing disease-transmitting mosquitoes using odor-baited stations - The Ifakara Odor-Baited Stations. Parasit Vectors 2010, 3:12.

25. Tan W, Sun L, Zhang D, Sun J, Qian J: Cloning and overexpression of ribosomal protein L39 gene from deltamethrin-resistant Culex pipiens pallens. Exp Parasitol 2007, 115:369-378

26. Zhang J, Yang $M$, Wang $W$, Sun $H, X u$ Y: prag01, a novel deltamethrinresistance-associated gene from Culex pipiens pallens. Parasitol Res 2011, 108:417-423.

27. Xu Y, Yang M, Sun J, Qian J, Zhang D: Glycogen branching enzyme: a novel deltamethrin resistance-associated gene from Culex pipiens pallens. Parasitol Res 2008, 103:449-458.

28. Sun L, Dong H, Guo C, Qian J, Sun J: Larvicidal activity of extracts of Ginkgo biloba exocarp for three different strains of Culex pipiens pallens. J Med Entomol 2006, 43:258-261.

29. Gong $M Q, G u Y, H u$ XB, Sun $Y, M a$ L: Cloning and overexpression of CYP6F1 a cytochrome P450 gene from deltamethrin-resistant Culex pipiens pallens. Acta Biochim Biophys Sin (Shanghai) 2005, 37:317-326.

30. Gong MQ, Shen B, Gu Y, Tian HS, Ma L: Serine proteinase over-expression in relation to deltamethrin resistance in Culex pipiens pallens. Arch Biochem Biophys 2005, 438:53-62

31. Zhu CL, Li JM, Tian HS, Ma L, Li XL, Wu GL: Cloning and identification of cytochrome $\mathrm{P} 450$ resistance related genes in the mosquito Culex pipiens pallens. Zhongguo Ji Sheng Chong Xue Yu Ji Sheng Chong Bing Za Zhi 2000, 18:263-268.

32. He J, Sun $H$, Zhang D, Sun Y, Ma L: Cloning and characterization of 605 ribosomal protein L22 (RPL22) from Culex pipiens pallens. Comp Biochem Physiol B Biochem Mol Biol 2009, 153:216-222.

33. Hu X, Wang W, Zhang D, Jiao J, Tan W: Cloning and characterization of $40 \mathrm{~S}$ ribosomal protein $\mathrm{S} 4 \mathrm{gene}$ from Culex pipiens pallens. Comp Biochem Physiol B Biochem Mol Biol 2007, 146:265-270.

34. Shen B, Tian HS, Ma L, Li XL, Zhen SZ, Zhou DH, Zhu CL: Cloning and sequence analysis of full-length trypsin cDNA of Culex pipiens pallens. Sheng Wu Hua Xue Yu Sheng Wu Wu Li Xue Bao (Shanghai) 2002, 34:28-32.

35. Tian HS, Zhu CL, Gao XH, Ma L, Shen B: Cloning and identification of deltamethrin-resistance or susceptibility associated genes of Culex pipiens pallens. Zhongguo Ji Sheng Chong Xue Yu Ji Sheng Chong Bing Za Zhi 2001, 19:193-197.

36. Yang M, Qian J, Sun J, Xu Y, Zhang D: Cloning and characterization of myosin regulatory light chain (MRLC) gene from Culex pipiens pallens. Comp Biochem Physiol B Biochem Mol Biol 2008, 151:230-235.

37. Zhu C, Li Y, Sun L, Li J, Gao X, Ye B: Genetic analysis of deltamethrin resistance in Culex pipiens pallens. Zhongguo Ji Sheng Chong Xue Yu Ji Sheng Chong Bing Za Zhi 1998, 16:21-24.

38. Meehan HA, Connell GJ: The hairpin loop but not the bulged $C$ of the iron responsive element is essential for high affinity binding to iron regulatory protein-1. J Biol Chem 2001, 276:14791-14796.

doi:10.1186/1756-3305-4-215

Cite this article as: Tan et al:: Molecular cloning and preliminary function study of iron responsive element binding protein 1 gene from cypermethrin-resistant Culex pipiens pallens. Parasites \& Vectors 2011 4:215. 